\title{
Visual impairment and associated factors among primary school children in Gurage Zone, Southern Ethiopia
}

\author{
Gashaw Garedew Woldeamanuel ${ }^{1}$, Mohammed Derese Biru² ${ }^{2}$ Teshome Gensa Geta ${ }^{1}$, Birhan Abera Areru ${ }^{2}$
}

1. Department of Biomedical Sciences, School of Medicine, College of Medicine and Health Sciences, Wolkite University, Wolkite, Ethiopia.

2. Department of Statistics, College of Natural and Computational Sciences, Wolkite University, Wolkite, Ethiopia.

\begin{abstract}
Background: Visual impairment is one of the major public health problems worldwide, especially in developing countries.

Objective: To determine the prevalence of visual impairment and its associated factors among school children in Gurage Zone, Southern Ethiopia

Methods: A cross sectional study was conducted in eight primary schools of Gurage Zone. A total of 1064 pupils, of whom589 boys and 475 girls were selected using multistage sampling technique. Socio-demographic characteristics of the participants were collected using structured questionnaires and visual acuity was measured using Snellen's chart. Logistic regression analysis was used to determine the associated factors of visual impairment.
\end{abstract}

Results: The prevalence of visual impairment was $5.2 \%$. Factors significantly associated with visual impairment were age group of 13-18 years $(\mathrm{AOR}=9.44,95 \% \mathrm{CI}=3.83-23.25)$, school grade level of $5-8(\mathrm{AOR}=2.97,95 \% \mathrm{CI}=1.23-7.17)$, rural residents $(\mathrm{AOR}=2.59,95 \% \mathrm{CI}=1.22-5.54)$, family's monthly income of less than 2000 Ethiopian Birr $(\mathrm{AOR}=2.87,95 \% \mathrm{CI}$ $=1.08-7.61)$ and visually impaired parents $(\mathrm{AOR}=2.16,95 \% \mathrm{CI}=1.06-4.39)$.

Conclusion: This study found that the prevalence of visual impairment was 5.2\%.

Keywords: Visual impairment, primary school children, Gurage Zone, Southern Ethiopia.

DOI: https://dx.doi.org/10.4314/ahs.v20i1.60

Cite as: Woldeamanuel GG, Biru MD, Geta TG, Areru BA. Visual impairment and associated factors among primary school children in Gurage Zone, Southern Ethiopia. Afri Health Sci. 2020;20(1):533-42. https:// dx.doi.org/10.4314/abs.v20i1.60

\section{Introduction}

Visual impairment has a negative effect on the overall development of the countries ${ }^{1}$. It is one of the major public health problems worldwide, especially in developing countries $^{2}$. According to WHO 2017 report, an estimated 253 million people live with vision impairment: 36 million are blind and 217 million have moderate to severe visual impairment ${ }^{3}$.

\section{Corresponding author: \\ Gashaw Garedew Woldeamanuel, \\ Department of Biomedical Sciences, \\ School of Medicine, \\ College of Medicine and Health Sciences, \\ Wolkite University, \\ P.O. Box 07, Wolkite, Ethiopia.}

Email: gashawgaredew05@gmail.com
Children below the age of 15 years are identified as a risk group to develop visual impairment and blindness ${ }^{3}$. The prevalence of visual impairment among children is high in the poorest regions of Africa and $\mathrm{Asia}^{4}$. This might be related to the nutritional, health, and socioeconomic status of that country ${ }^{5}$. If early diagnosis and treatment are used, visual impairment can be corrected easily1. Therefore, early detection and treatment of visual problem is important to prevent long term visual disability and to enhance overall quality of life ${ }^{5}$.

There are many causes of visual impairment in children such as refractive error, corneal opacities ${ }^{6}$, retinopathy of prematurity ${ }^{7}$, cataract and trachoma ${ }^{5}$. Different studies reported that, the most common cause of visual impairment in children is refractive errors ${ }^{8,9}$. A high burden of uncorrected refractive errors has also been reported in multiple studies conducted among school-aged children ${ }^{8,10,11}$. The WHO and the International Agency for Prevention of

(C) 2020 Woldeamanuel GG et al. Licensee African Health Sciences. This is an Open Access article distributed under the terms of the Creative commons Attribution License (https://creativecommons.org/licenses/BY/4.0), which permits unrestricted use, distribution, and reproduction in any medium, provided the original work is properly cited.
} 
Blindness have included uncorrected refractive error to the prevention of blindness agenda and have developed strategies for the elimination of this avoidable cause of visual impairment ${ }^{12}$. The leading causes of blindness and visual impairment in developing countries are generally associated with poverty, illiteracy and deprivation, most commonly found in rural and undeveloped areas ${ }^{13}$. Additionally, majority of the cases are due to either preventable or curable causes ${ }^{14}$.

Ethiopia is believed to have one of the world's highest rates of blindness and low vision ${ }^{14}$. However, approximately $80 \%$ of blindness in Ethiopia was believed to be avoidable; i.e., preventable or curable ${ }^{14}$. There are only few small scale studies conducted in different parts of the country and reported a prevalence of visual impairment in children as $7.24 \% 0^{1}, 5.8 \% 0^{5}$ and national prevalence of low vision as $3.7 \%{ }^{14}$.

Vision screening in children is important for early detection of visual impairment, identification of possible causes and management at an early stage ${ }^{15,16}$. Studies conducted in different parts of the world showed an increase/ rise in the prevalence of visual impairment among school children. Even though there were few studies conducted in different parts of our country, recent data were lacking to accurately determine the magnitude and causes of visual impairment among school children in Gurage Zone, Southern Ethiopia. Therefore the aim of this study was to determine the prevalence and associated factors of visual impairment among primary school children in $\mathrm{Gu}-$ rage Zone, Southern Ethiopia.

\section{Methods}

A School based cross sectional study was conducted in
Gurage Zone, Southern Ethiopia. Gurage Zone is found in Southern Ethiopia and in the year 2017/18, this zone had a total of 456 primary schools (grade $1-8$ ). In the same academic year, 321,664 students, of whom 169,659 boys and 152,005 girls were enrolled in primary schools of Gurage Zone (Gurage Zone education office; 2018 annual report). This study was conducted in eight primary schools from April 1 - June 5, 2018. The selected schools were located in Wolkite, Abeshge, Kebena and Cheha district of Gurage Zone, Southern Ethiopia.

The participants of this study were primary school children in the randomly selected schools who met the inclusion criteria. An inclusion criterion for this study was all primary school children who gave us assent and those who had a written consent from the parents. Students who had difficulty in communicating and non-Ethiopian citizens were excluded from the study.

The required sample size was calculated using statistical formula for single population proportion based on the following assumptions: $7.24 \%$ prevalence of visual impairment as reported in a previous study ${ }^{1}, 2 \%$ level of precision with $95 \%$ confidence interval and design effect of 1.5 . By considering $10 \%$ non response rate, the final sample size was 1064 .

The study participants were selected through multistage sampling technique. Initially, four districts from the fifteen districts of Gurage zone were selected randomly using lottery method. Then, two schools from each district, a total of eight primary schools were selected using simple random sampling. Finally, the total sample size was allocated to the selected schools based on probability proportional to size sampling and simple random sampling method was employed to select study participants (Figure 1). 


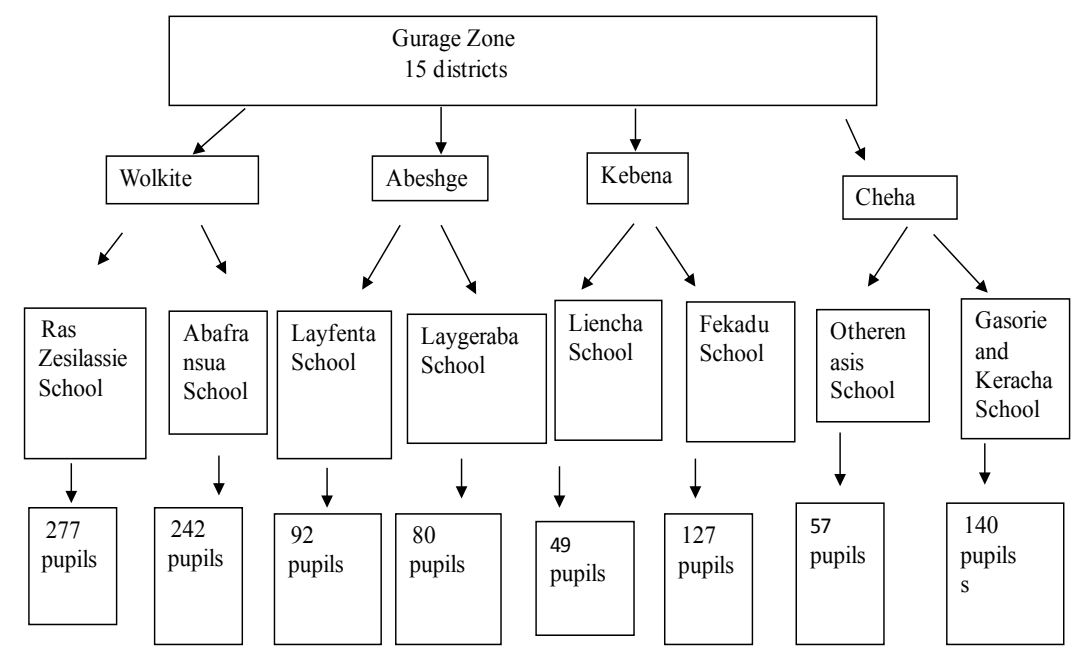

Figure 1: Flow chart depicting sampling procedures

Data were collected by optometrists, ophthalmic nurses and ophthalmologists. Then optometrists and ophthalmic nurses did a face to face interview using structured questionnaires to obtain information on the socio-demographic and other related characteristics of the participants. They also measured the visual acuity using the illiterate $\mathrm{E}$ chart in a quiet and properly illuminated room. Each eye was tested separately at a distance of 6-meter and the procedures were repeated three times then the best result was taken. Children with VA $<6 / 12$ in one or both eyes underwent further ophthalmic examination by ophthalmologist. The ophthalmologist performed detailed ocular examinations to establish the principal causes of visual impairment. Parents with visual impairment were identified by using the same procedure, as in pupils. However, the specific causes of visual impairment among parents were not determined.

The WHO categories of visual impairment were used for this study ${ }^{17}$. Visual impairment was defined as presenting visual acuity (VA) of $<6 / 12$ in the better eye. It was further classified into mild $(<6 / 12$ to $\geq 6 / 18)$, moderate $(<$ $6 / 18$ to $\geq 6 / 60)$ and severe visual impairment $(<6 / 60$ to $\geq 3 / 60)$.

To maintain accuracy, consistency and reliability of data, the data collectors were trained before the actual data collection. The questionnaires were pre tested and the nec- essary corrections were made.

The collected data were coded, cleaned, checked for completeness and entered in to CSPro Version 6.2 and then exported to SPSS version 20 for analysis. Frequency and percentages were computed to present the socio-demographic characteristics of the study participants. Binary logistic regression analysis was also performed to identify associated factors of visual impairment. Variables with $\mathrm{p}$ value $\leq 0.25$ in the bivariate analysis were entered into multiple logistic regression analysis. The results of the analysis were presented with texts, tables and figures. A p-value of less than 0.05 was considered as statistically significant.

Ethical approval was obtained from Institutional Review Board of Wolkite University with ethical approval reference number IRB/55/8/2010. Then, letter of permission to conduct the study was obtained from Gurage Zone Education Bureau. Data was collected after obtaining written informed consent from the parents or guardians of the children and assent from each pupil. Confidentiality was maintained throughout the study. Children, requiring further treatment were referred to the nearby hospitals /clinics.

\section{Results}

\section{Socio-demographic characteristics}

A total of 1064 school children aged between 7 and 18 
years consisting of $589(55.4 \%)$ males and 475 (44.6\%) females participated in this study. The mean age of the participants was $11.4 \pm 2.54$ years, within the age range of 7-18 years old. Majority, 683(64.2\%) of the students live in the rural areas (Table 1).

Table 1: Socio-demographic characteristics of the students attending primary schools in Gurage Zone, Southern Ethiopia, 2018 ( $n=1064)$

\begin{tabular}{ll}
\hline Variables & \multicolumn{1}{c}{$\mathbf{n}(\mathbf{\%})$} \\
\hline Sex & \\
Male & $589(55.4)$ \\
Female & $475(44.6)$ \\
Age (years) & \\
$7-12$ & $669(62.9)$ \\
$13-18$ & $395(37.1)$ \\
Religion & \\
Muslim & $645(60.6)$ \\
Orthodox & $323(30.4)$ \\
Protestant & $33(3.1)$ \\
Catholic & $57(5.4)$ \\
Others & $6(0.6)$ \\
Grade & \\
1-4 & $546(51.3)$ \\
5-8 & $518(48.7)$ \\
Residence & \\
Urban & $381(35.8)$ \\
Rural & $683(64.2)$ \\
\hline
\end{tabular}

\section{Prevalence of visual impairment}

The prevalence of visual impairment $(\mathrm{VA}<6 / 12)$ in the better eye was $55(5.2 \%$ [95\% CI, 3.9- 6.6]). Out of the total study participants, $41(3.9 \%), 12(1.1 \%)$ and $2(0.2 \%)$ participants had mild, moderate and severe visual impairment respectively. The prevalence of moderate visual impairment was found to be relatively higher among male students, age group of 7-12 years, school grade level of 1- 4 and rural residents (Table 2). 
Table 2: Distribution of visual impairment among visually impaired school children in Gurage Zone, Southern Ethiopia, $2018(\mathrm{n}=55)$

\begin{tabular}{|c|c|c|c|c|}
\hline \multirow[t]{2}{*}{ Variables } & \multicolumn{3}{|c|}{ Visual impairment } & \multirow[b]{2}{*}{$\begin{array}{l}\text { Total } \\
\text { n (\%) }\end{array}$} \\
\hline & $\begin{array}{l}\text { Mild } \\
\text { n (\%) }\end{array}$ & $\begin{array}{c}\text { Moderate } \\
\text { n (\%) }\end{array}$ & $\begin{array}{c}\text { Severe } \\
\text { n (\%) } \\
\end{array}$ & \\
\hline \multicolumn{5}{|l|}{ Sex } \\
\hline Male & $26(47.3)$ & $7(12.7)$ & $0(0)$ & $33(60)$ \\
\hline Female & $15(27.3)$ & $5(9.1)$ & $2(3.6)$ & $22(40)$ \\
\hline \multicolumn{5}{|l|}{ Age (years) } \\
\hline $7-12$ & $10(18.2)$ & $7(12.7)$ & $1(1.8)$ & $18(32.7)$ \\
\hline 13-18 & $31(56.4)$ & $5(9.1)$ & $1(1.8)$ & $37(67.3)$ \\
\hline \multicolumn{5}{|l|}{ Grade } \\
\hline $1-4$ & $13(23.6)$ & $10(18.2)$ & $1(1.8)$ & $24(43.6)$ \\
\hline $5-8$ & $28(51)$ & $2(3.6)$ & $1(1.8)$ & $31(56.4)$ \\
\hline \multicolumn{5}{|l|}{ Residence } \\
\hline Urban & $9(16.4)$ & $1(1.8)$ & $0(0)$ & $10(18.2)$ \\
\hline Rural & $32(58.2)$ & $11(20)$ & $2(3.6)$ & $45(81.8)$ \\
\hline Total & $41(74.6)$ & $12(21.8)$ & $2(3.6)$ & $55(100)$ \\
\hline
\end{tabular}

\section{Associated factors of visual impairment}

Binary logistic regression analysis was performed to identify the risk factors of visual impairment. The factors which were significantly associated with visual impairment were age group of $13-18$ years $(\mathrm{AOR}=9.44,95 \%$ $\mathrm{CI}=3.83-23.25, \mathrm{p}<0.001)$, school grade level of $5-8$ $(\mathrm{AOR}=2.97,95 \% \mathrm{CI}=1.23-7.17, \mathrm{p}=0.015)$, rural residents $(\mathrm{AOR}=2.59,95 \% \mathrm{CI}=1.22-5.54, \mathrm{p}=0.014)$, family's monthly income of $<2000$ Ethiopian Birr (AOR $=2.87,95 \% \mathrm{CI}=1.08-7.61, \mathrm{p}=0.035)$ and presence of visually impaired parents $(\mathrm{AOR}=2.16,95 \% \mathrm{CI}=1.06$ - 4.39, $\mathrm{p}=0.033)$. However; sex, maternal education and experience of medical visit had no significant association with visual impairment (Table 3). 
Table 3: Factors associated with visual impairment among primary school children in Gurage Zone, Southern Ethiopia, 2018 ( $\mathrm{n}=1064)$

\begin{tabular}{|c|c|c|c|c|}
\hline \multirow[t]{2}{*}{ Variables } & \multicolumn{2}{|c|}{ Visual impairment } & \multirow[t]{2}{*}{$\operatorname{COR}(95 \% \mathrm{CI})$} & \multirow[t]{2}{*}{ AOR (95\% CI) } \\
\hline & Yes $(\%)$ & No $(\%)$ & & \\
\hline \multicolumn{5}{|l|}{ Sex } \\
\hline Male & $33(5.6)$ & $556(94.4)$ & 1.00 & 1.00 \\
\hline Female & $22(4.6)$ & $453(95.4)$ & $0.82(0.47-1.42)$ & $0.80(0.44-1.45)$ \\
\hline \multicolumn{5}{|l|}{ Age (years) } \\
\hline $7-12$ & $18(2.7)$ & $651(97.3)$ & 1.00 & 1.00 \\
\hline 13-18 & $37(9.4)$ & $358(90.6)$ & $3.74(2.09-6.66)$ & $9.44(3.83-23.25)^{*}$ \\
\hline \multicolumn{5}{|l|}{ School grade } \\
\hline $1-4$ & $24(4.4)$ & $522(95.6)$ & 1.00 & 1.00 \\
\hline $5-8$ & $31(6.0)$ & $487(94)$ & $1.38(0.80-2.39)$ & $2.97(1.23-7.17)^{*}$ \\
\hline \multicolumn{5}{|l|}{ Residence } \\
\hline Urban & $10(2.6)$ & $371(97.4)$ & 1.00 & 1.00 \\
\hline Rural & $45(6.6)$ & $638(93.4)$ & $2.62(1.30-5.25)$ & $2.59(1.22-5.54)^{*}$ \\
\hline \multicolumn{5}{|c|}{ Family income /month (ETB) } \\
\hline$<2000$ & $22(9.5)$ & $209(90.5)$ & $4.19(1.67-10.54)$ & $2.87(1.08-7.61)^{*}$ \\
\hline $2,000-5000$ & $16(7.4)$ & $201(92.6)$ & $3.17(1.22-8.25)$ & $2.63(0.96-7.15)$ \\
\hline $5,001-10,000$ & $11(3)$ & $360(97)$ & $1.22(0.44-3.33)$ & $1.01(0.36-2.83)$ \\
\hline$>10,000$ & $6(2.4)$ & $239(97.6)$ & 1.00 & 1.00 \\
\hline \multicolumn{5}{|c|}{ Parents with impaired visual acuity } \\
\hline Yes & $13(9.6)$ & $123(90.4)$ & $2.23(1.16-4.27)$ & $2.16(1.06-4.39)^{*}$ \\
\hline No & $42(4.5)$ & $886(95.5)$ & 1.00 & 1.00 \\
\hline \multicolumn{5}{|c|}{ Maternal education } \\
\hline Illiterate & $24(9.7)$ & $224(90.3)$ & $2.84(0.65-12.39)$ & $2.84(0.60-13.38)$ \\
\hline Primary & $26(4.1)$ & $609(95.9)$ & $1.13(0.26-4.89)$ & $1.29(0.28-6.00)$ \\
\hline Secondary & $3(2.4)$ & $123(97.6)$ & $0.65(0.11-3.98)$ & $0.96(0.15-6.44)$ \\
\hline College + & $2(3.6)$ & $53(96.4)$ & 1.00 & 1.00 \\
\hline \multicolumn{5}{|l|}{ Medical visit } \\
\hline No visit & $41(4.7)$ & $823(95.3)$ & $2.14(0.29-15.94)$ & $2.12(0.28-16.40)$ \\
\hline During symptoms & $13(8.3)$ & $143(91.7)$ & $3.91(0.49-30.74)$ & $3.16(0.38-26.44)$ \\
\hline Regularly & $1(2.3)$ & $43(97.7)$ & 1.00 & 1.00 \\
\hline
\end{tabular}

\section{Causes of visual impairment}

In this study, the causes of visual impairment were determined and refractive error was the leading cause of visual impairment. Twenty seven (49.1\%) of the visually im- paired children had refractive error. Among the students with refractive error, $16(59.3 \%), 5(18.5 \%)$ and $6(22.2 \%)$ had myopia, hyperopia and astigmatism, respectively. The cause of visual impairment was unexplained in $6(10.9 \%)$ children (Figure 2). 


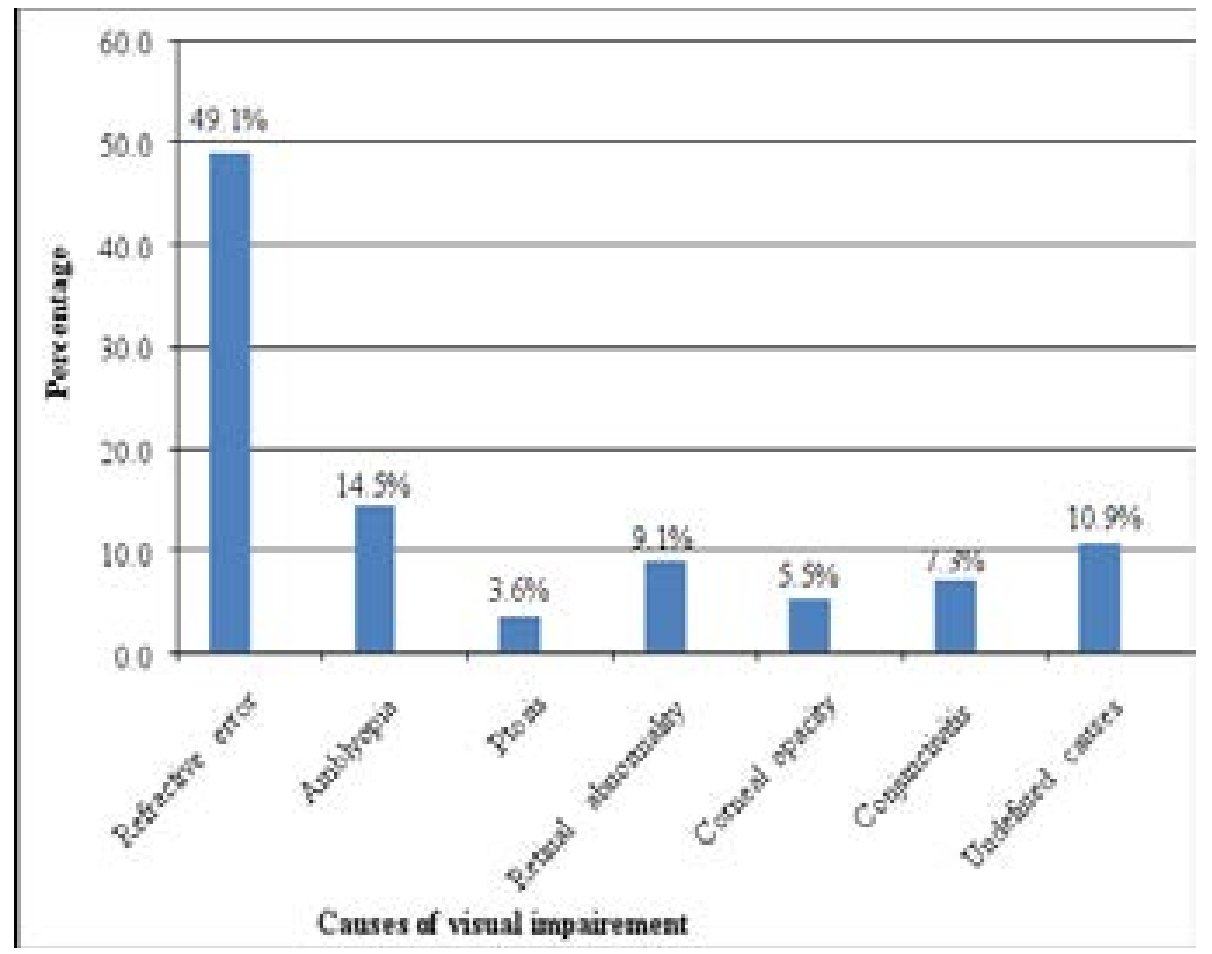

Figure 2: Causes of visual impairment among visually impaired school children in Gurage Zone, Southern Ethiopia, $2018(n=55)$

\section{Discussion}

Undetected vision impairment in school children affects the learning abilities of school children which can adversely affect a child's education, occupation and socioeconomic status for life. Visually impaired children also suffer a number of physical and social consequenc$\mathrm{es}^{18}$. Screening or vision testing in children should be performed to detect vision problems and to reduce the risk of blindness. The objective of this study was to determine the prevalence of visual impairment and its associated factors among school children in Gurage Zone, Southern Ethiopia.

In the present study, the prevalence of visual impairment $(\mathrm{VA}<6 / 12)$ in the better eye was 5.2\% (95\% CI, 3.9 6.6). This finding was comparable with studies done in Ethiopia ${ }^{5}$ and Sudan $^{8}$, which were $5.8 \%$ and $6.4 \%$ respectively. This could be due to similarities in the techniques of visual acuity determination and definition of visual impairment used in the studies. Moreover, the participants of these studies had nearly similar age group. However, the result of this study is lower than the prevalence of visual impairment among children in Tanzania, which was $10.2^{\%} \%^{19}$. The prevalence of visual impairment among school age children was also reported in other studies from different countries; $6.9 \%$ in Nigeria ${ }^{20}, 7.7$
$\%$ in China ${ }^{21}$ and $2.7 \%$ in Brazil ${ }^{22}$. The differences in the findings could be due to variations in study population, study definitions and techniques of visual acuity determination.

In agreement with the study done by Saif $\mathrm{H}$ Alrasheed et $\mathrm{al}^{8}$ in Sudan, the prevalence of visual acuity impairment was slightly higher among males $(5.6 \%)$ as compared to females $(4.6 \%)$.

However, there was no significant association between gender and prevalence of visual impairment $(\mathrm{p}=0.46)$. Other studies ${ }^{8,20,21,23}$ found no significant association between gender and visual impairment.

Our finding also showed that higher grade level was associated with high prevalence of visual impairment $(\mathrm{p}=$ 0.015). In line with this finding, various studies ${ }^{24-26}$ showed that higher education level increases the risk of visual impairment particularly myopia. The association of visual impairment with school grade level may be attributed to more hours of near work and indoor activities ${ }^{27}$. Intensive indoor/near activities could result in retinal defocus which leads to axial length elongation, thereby causing visual impairment particularly myopia ${ }^{27,28}$.

In the present study, the odds of visual impairment among students in the age group of 13-18 years were 
higher $(\mathrm{OR}=9.44,95 \% \mathrm{CI}=3.83-23.25)$ compared to those students in the age group of 7-12 years. Our finding also showed that there was statistically significant association between age and visual acuity impairment ( $p$ $\leq 0.001)$. This finding was consistent with other studies which reported that prevalence of visual impairment increases with increase in age $e^{8,29,30}$. The association of age with visual impairment in this study could be attributed to children's involvement in more schooling hours and near/indoor activities as they progress to higher age.

In the present study, the risk of visual impairment was higher among the students whose parents were visually impaired than those who had no visually impaired parents. In agreement with our findings, studies by Darge et $\mathrm{al}^{5}$ and Mutti ${ }^{31}$ reported that the risk of inheriting impaired visual acuity was increased if parents had similar problems. Refractive errors can be inherited. If one or more parents have a refractive error, their child is more likely to suffer from refractive error ${ }^{32}$. Heritability estimates for refractive error range from $40 \%$ to $94 \%{ }^{33}$. Hence, the development of visual impairment could be mediated by environmental and genetic risk factors ${ }^{34}$.

The present study showed that the prevalence of visual impairment was higher among individuals living in rural area than urban areas. In line with the current study, studies in Korea ${ }^{35}$ and Ethiopia ${ }^{14}$ showed that subjects living in rural area had a higher prevalence of visual impairment and they carry greater risk for eye problems than urban residents. This might be due to different barriers for getting eye care services including financial constraint for the services and other costs associated with travelling to health facilities ${ }^{36}$. Urban residents have better access to multiple health care service providers than rural residents, who often depend on inadequately equipped health facilities $^{37}$.

The current study found that visual impairment was significantly associated with low family income $(p=0.035)$. Participants with family's monthly income of less than 2000 Ethiopian Birr were 2.87 times more likely to develop visual impairment than those with family income of $>10,000$ Ethiopian Birr $(\mathrm{OR}=2.87,95 \% \mathrm{CI}=1.08$ 7.61). In line with this result, Andhra Pradesh study reported that the risk of visual impairment including blindness was found to increase with decrease in monthly income ${ }^{38}$. Jaggernath et al study also reported that the burden of vision impairment is high in people with low income ${ }^{39}$. Poor people are subjected to limited access to employment opportunities and face different barriers in accessing eye health services which in turn affects eye health ${ }^{39}$. Moreover, students from low socioeconomic status spend longer studying their lessons in badly illuminated, crowded rooms which can affect ocular growth and refractive error is gaining scientific credence ${ }^{40}$.

Our study showed that uncorrected refractive error was the most common cause of visual impairment. Similar findings were reported in several studies, ${ }^{9,30,41-44}$. The present study found refractive error as the major cause of visual impairment in $49.1 \%$ of the children with visual impairment. The result of this study is comparable to the prevalence of refractive error among visually impaired children in Sudan, which was $57 \%{ }^{8}$. Amblyopia was the second cause of visual impairment in our study, as in other study conducted in Ethiopian ${ }^{5}$. The prevalence of amblyopia was $14.5 \%$, which was higher than $9.4 \%$ reported in South Africa ${ }^{41}$ and $6 \%$ in Ghana ${ }^{45}$. In this study, retinal abnormality also accounts for a significant proportion of visual impairment (9.1\%). A similar study from Ethiopia indicated that retinal abnormality accounts for about $5.4 \%$ of the visual impairment1. Differences in the findings could be due to variations in study population, genetic susceptibility among different races and the methods used. Overall, large proportions of the causes of visual impairment in this study are avoidable (preventable or treatable).This indicates the need for timely provision of preventive and curative eye care services.

The limitation of this study was the use of school based study (institution based) rather than population based. Hence, the study didn't include non school children because of lack of resources. Despite the above limitation, this study provides valuable information about the burden of visual impairment and associated factors among school children in Gurage Zone, Southern Ethiopia.

\section{Conclusion}

The burden of visual impairment among school children in Gurage Zone was high. Various factors like age, school grade, residence, family income and parents with impaired visual acuity were significantly associated with visual impairment. Uncorrected refractive error was the commonest cause of visual impairment among school children. This indicates the need for appropriate eye care services to reduce the burden of visual impairment. Further population based study is recmmended to assess the visual status of non school going children.

African Health Sciences Vol 20 Issue 1, March, 2020 


\section{Acknowledgments}

We would like to express our deepest gratitude to Wolkite University for funding this research project. We would like also to thank Gurage Zone Education Bureau, school directors, teachers, those who helped in data collection, supervision and respondents for their cooperation.

\section{References}

1. Bezabih L, Abebe TW, Fite RO. Prevalence and factors associated with childhood visual impairment in Ethiopia. Clinical Ophthalmology. 2017; 11:1941 -1948.

2. Congdon NG, Friedman DS, Lietman T. Important causes of visual impairment in the world today. The Journal of the American Medical Association. 2003; 290(15):2057 -2060 .

3. World Health Organization. Vision impairment and blindness, WHO fact sheet Updated, 2017. http://www. worldblindunion.org/English/resources/Documents/ Factsheet $\% 20$ about $\% 20$ vision $\% 20$ impairment $\% 20$ and $\% 20$ blindness.docx (Accessed on 16 October 2018).

4. Bourne RR, Flaxman SR, Braithwaite T, Cicinelli MV, Das A, Jonas JB, et al. Magnitude, temporal trends, and projections of the global prevalence of blindness and distance and near vision impairment: a systematic review and meta-analysis. The Lancet Global Health. 2017;5(9):888 $-\neg \neg 897$.

5. Darge HF, Shibru G, Mulugeta A, Dagnachew YM. The Prevalence of Visual Acuity Impairment among School Children at Arada Subcity Primary Schools in Addis Ababa, Ethiopia. Journal of Opbthalmology. 2017;1-7.

6. Whitcher JP, Srinivasan M, Upadhyay MP. Corneal blindness: A global perspective. Bull World Health Organanization. 2001;79:214 - 221.

7. Munoz B, West SK. Blindness and visual impairment in the Americas and the Caribbean. British Journal of Ophthalmology. 2002;86:498 -504.

8. Alrasheed SH, Naidoo KS, Clarke-Farr PC. Prevalence of visual impairment and refractive error in school-aged children in South Darfur State of Sudan. African Vision and Eye Health. 2016; 75 (1):1- 9.

9. Aniza I, Azmawati MN, Jamsiah M, Idayu BI, Mae Lynn CB. Prevalence of visual acuity impairment and its associated factors among secondary school students in Beranang, Selangor. Malaysian Journal of Public Health Medicine. 2012;12(1):39 - 44.

10. Gupta A, Lal R, Mazta SR, Sharma D. Prevalence of Refractive Errors, Color Vision Defects and Other Ocular Disorders in School-going Children: Primary Screen- ing by School Teachers. Journal of International Medical Sciences Academy. 2012;25 (4):223 - 224.

11. Rustagi N, Uppal Y, Taneja DK. Screening for visual impairment: Outcome among schoolchildren in a rural area of Delhi. Indian Journal of Ophthalmology. 2012;60:203-206.

12. Holden BA. Uncorrected refractive error: The major and most easily avoidable cause of vision loss. Community Eye Health. 2007; 20 (63):37- 39.

13. Teshome T. Prevalence and causes of blindness in Merhabete, North Shoa, Ethiopia. Ethiopian Journal of Health Development. 2002;16 (1):71 - 76.

14. Berhane Y, Worku A, Bejiga A, Adamu L, Alemayehu W, Bedri A, et al. Prevalence and causes of blindness and low vision in Ethiopia. Ethiopian Journal of Health Development. 2007; 21(3): $204-210$.

15. Register SJ. Visual acuity and stereopsis screening results in an underserved community. Optometry-Journal of the American Optometric Association. 2010; 81(4):200 - 204. 16. Opubiri I, Pedro-Egbe C. Screening for refractive error among primary school children in Bayelsa state, Nigeria. Pan African Medical Journal. 2013; 14: 74. PubMed doi:10.11604/pamj.2013. 14. 74.1345 PubMed

17. WHO. International statistical classification of diseases and related health problems (ICD-11), 2018. https:// icd.who.int/browse11/1 m/en\#/http://id.who.int/icd/ entity/1103667651 (Accessed on 15 February 2019)

18. Taylor HR. Refractive errors: magnitude of the need. Community Eye Health. 2000; 13 (33): 1-2.

19. Wedner SH, Ross DA, Balira R, Kaji L, Foster A. Prevalence of eye diseases in primary school children in a rural area of Tanzania. British Journal of Ophthalmology. 2000; 84(11):1291-1293.

20. Megbelayin O, Asana E. Visual impairment among school children calabar vision screening survey in secondary schools (CVS4 Study). The Internet Journal of Ophthalmology and Visual Science. 2013; 10:1-7.

21. Pi L, Chen L, Liu Q, Ke N, Fang J, Zhang S, et al. Prevalence of Eye Diseases and Causes of Visual Impairment in School-Aged Children in Western China. Journal of Epidemiology. 2012;22:37- 44.

22. Salomao SR, Cinoto RW, Berezovsky A, Mendieta L, Nakanami CR, Lipener C, et al. Prevalence and causes of visual impairment in low-middle income school children in São Paulo, Brazil. Investigative Ophthalmology and Visual Sciences. 2008;49(10):4308 - 4313.

23. Datta A, Bhardwaj N, Patrikar SR, Bhalwar R. Study of disorders of visual acuity among adolescent school- 
children in Pune. Medical Journal Armed Forces India. 2009;65(1):26 -27.

24. Paudel P, Ramson P, Naduvilath T, Wilson D, Phuong HT, Ho SM, et al. Prevalence of vision impairment and refractive error in school children in Ba Ria - Vung Tau province, Vietnam. Clinical \& Experimental Ophthalmology. 2014; 42(3):217- 226.

25. He M, Huang W, Zheng Y, Hiang L, Ellwein LB. Refractive error and visual impairment in school children in rural southern China. Ophthalmology. 2007;114:374 - 382 PubMed .

26. Sapkota YD, Adhikari BN, Pokharel GP, Poudyal BK, Ellwein LB. The prevalence of visual impairment in school children of upper-middle socioeconomic status in Kathmandu. Ophthalmic Epidemiology. 2008;15:17-23.

27. Atowa UC, Munsamy AJ, Wajuihian SO. Prevalence and risk factors for myopia among school children in Aba, Nigeria. African Vision and Eye Health. 2017;76(1):1-5.

28. Myrowitz EH. Juvenile myopia progression, risk factors and interventions. Saudi Journal of Ophthalmology. 2012;26(3):293 - 297.

29. Livingston PM, McCarty CA, Taylor HR. Visual impairment and socioeconomic factors. The British Journal of Ophthalmology.1997;81:574 - 577.

30. Goh PP, Abqariyah Y, Pokharel GP, Ellwein LB. Refractive error and visual impairment in school-age children in Gombak district, Malaysia. American Academy of Ophthalmology. 2005;112(4):678 - 685.

31. Mutti DO. Can we conquer myopia? Review of Optometry. 2001;138:80 - 92.

32. Guo L, Yang J, Mai J, Du X, Guo Y, Li P, et al. Prevalence and associated factors of myopia among primary and middle school-aged students: a school-based study in Guangzhou. Eye. 2016;30(6):796 -804

33. Young TL, Metlapally R, Shay AE. Complex trait genetics of refractive error. Archives of Ophthalmology. 2007;125(1):38 - 48 .

34. Goldschmidt E, Jacobsen N. Genetic and environmental effects on myopia development and progression. Eye. 2014;28(2):126 - 133.

35. Rim TH, Nam JS, Choi M, Lee SC, Lee CS. Preva- lence and risk factors of visual impairment and blindness in Korea: the Fourth Korea National Health and Nutrition Examination Survey in 2008-2010. Acta ophthalmologica. 2014;92(4):320 - 332.

36. Melese M, Alemayehu W, Friedlander E, Courtright P. Indirect Costs Associated with Accessing Eye Care Services as a Barrier to Service Use in Ethiopia. Tropical Medicine and International Health. 2004; 9:426 - 431.

37. Baker RS, Bazargan M, Bazargan-Hejazi S, Calderon JL. Access to Vision Care in an Urban Low- Income Multi-Ethnic Population. Ophthalmic Epidemiology. 2005;12:1 -12.

38. Dandona R, Dandona L. Review of Findings of the Andhra Pradesh Eye Disease Study: Policy Implications for Eye-Care Services. Current Ophthalmology. 2001; 49:215 $-234$.

39. Jaggernath J, Overland L, Ramson P, Kovai V, Chan VF, Naidoo KS. Poverty and Eye Health. Health. 2014;6:1849 - 1860 .

40. Saad A, El Bayoumy BM. Environmental risk factors for refractive error among Egyptian schoolchildren. Eastern Mediterranean Health Journal. 2007; 13(4): 819 - 828. 41. Naidoo KS, Raghunandan A, Mashige KP, Govender P, Holden BA, Pokharel GP, et al. Refractive error and visual impairment in African children in South Africa. Investigative Ophthalmology and Visual Sciences. 2003; 44(9): $3764-3770$.

42. Murthy GV, Gupta SK, Ellwein LB, Munoz SR, Pokharel GP, Sanga L, et al. Refractive error in children in an urban population in New Delhi. Investigative Ophthalmology and Visual Sciences. 2002; 43(3): 623 - 631.

43. Nepal BP, Koirala S, Adhikari S, Sharma AK. Ocular morbidity in school children in Kathmandu. British Journal of Ophthalmology. 2003;87:531-534.

44. Alam H, Siddiqui MI, Jafri SI, Khan AS, Ahmed SI, Jafar M. Prevalence of refractive error in school children of Karachi. Journal of Pakistian Medical Association. 2008;58:322 - 325 .

45. Ovenseri-Ogbomo GO, Assien R. Refractive error in school children in Agona Swedru, Ghana. African Vision and Eye Health. 2010; 69(2):86 - 92. 